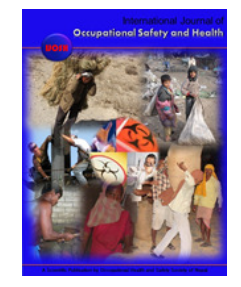

Available Online at http://nepjol.info/index.php/IJOSH

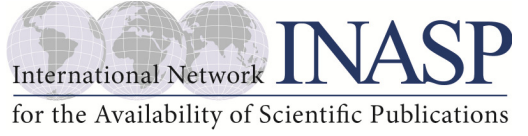

International Journal of Occupational Safety and Health, Vol 2. No 2 (2012) 3 - 7

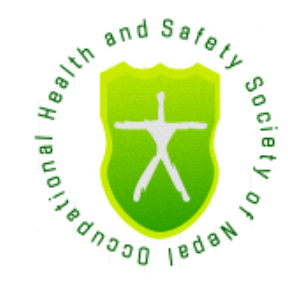

Original Article

\title{
A study of vibration exposure and work practices of Loader and Dozer operators in opencast mines
}

\author{
Bibhuti Bhusan Mandal, Krishnendu Sarkar, Veena Manwar \\ National Institute of Miners Health, JNARDDC Campus, Amravati Road, Wadi, \\ Nagpur, Maharastra
}

\section{Abstract:}

Exposure to whole body vibration (WBV) at work and development of musculoskeletal disorders are well linked. Vehicle vibrations are usually perceived to occur in vertical direction and are likely to cause lumbar disorders in operators. Vibration characteristics of the machines need to be studied and compared with work practices which may indicate nature of health risk to operators. This may help in developing specific action plans to control vibration related health risk.

The objectives of the study were, to measure and analyze vibration magnitudes, observe work practices of Loaders and Dozers, evaluate health risk to their operators and to formulate recommendations for control measures.

Frequency weighted Root Mean Square values of acceleration data was collected as per guidelines in ISO 2631 $-1: 1997$ using human vibration analyzers. WBV exposure of 40 (Forty) Loader and Dozer operators in eight opencast mines were evaluated to assess health risk using vibration magnitude and corresponding daily exposure durations.

The dominant axis of vibration in dozers was found to be $X$ (front to back) in $80 \%$ of the equipment. This is different from transporting equipment like Dumpers which have $Z$ axis as dominant axis of vibration. A continuous change of movement in forward and reverse direction and rash driving were found to be contributory factors for increased vibration intensity along X-axis. It was observed that $27(68 \%)$ of them showed moderate whereas $12(30 \%)$ equipment showed high health risk. It is suggested that vibration control measures should be designed and adopted based not only on the intensity but also on the dominant axis typical to the equipment and work practices.

Key Words: Whole body vibration; mine hazards; environmental health; occupational health; work practice; mining machinery.

\section{Introduction}

Use of Loaders and Dozers is an integral part of opencast mining for multiple reasons. Front end Loaders are used for loading coal or ore from a smaller height bench onto the trucks, railwagon or other conveying systems. It is also used to transports material over smaller distance e.g. from stockpile to crusher bin or handling dry or moist mill tailings for maintaining Corresponding Author: Bibhuti Bhusan Mandal

Email: bbmandal@hotmail.com

(c) 2012 IJOSH All rights reserved. tailing dam. It has a high degree of mobility, flexibility and productivity.[1]

Dozer is a diesel operated crawler mounted machine having a pusher blade attached to the front of it. The machine is usually crawler track mounted having hydraulic arrangements to raise the blade up and down. The concave straight blade's mould board is attached with cutting edge to dig into the soft rock or soil surface and doze the loose cut rock or mineral body. The machine is also used for land preparation, cleaning, construction and maintenance of haulage roads, benches etc. It 
can work on rough terrain, soft or wet ground at a gradient of $13^{0}$ to $14^{0} \cdot[1]$

At every stage of cycle of operations of Loaders and Dozers e.g. pushing or digging, loading, hauling and unloading, both these machines transmit vibration to the operator. Factors like rugged/ uneven terrain, speed, condition of seat and suspension etc. are important factors responsible for vibration generation and transmission. The parts of the body most likely to be affected by exposure to whole body vibration depend on the magnitude of vibration, distribution of the motion within the body, body postures, and the frequency of vibration, direction and duration.

In India, the Directorate General of Mines Safety (DGMS), recommends adoption of appropriate steps which would ensure desirable degree of comfort and protection required against hand arm and whole body vibration. However, no specific vibration limits (e.g. exposure limiting values) are prescribed.[2] Further, according to the Recommendations of 10th Conference on Safety in Mines, vibration studies of various mining machinery are required to be carried out before their introduction in mining operations as per ISO Standards.[3]

There is strong epidemiological evidence that occupational exposure to WBV is associated with increased risk of low back pain, sciatic pain, and degenerative changes in the spinal system, including lumbar inter-vertebral disc disorders.[4] In a critical review of musculoskeletal disorders and workplace factors, investigators of the National Institute of Occupational Safety and Health (NIOSH) observed that there is strong evidence of positive association between exposure to WBV and (low) back disorders.[5]

The current article aims to characterize the vibration emanating from Loaders and Dozers. The study also highlights differences in work practices of these machine operators with a view to formulate seat design parameters and adoption of good work practices in the user industry.

\section{Methods}

21 Dozers and 19 Loaders were studied in different opencast mines in India. Vibration magnitudes were measured with HVM 100 (Larson Davis make) vibration monitor and SVAN958 human vibration analyzer, in accordance with ISO 8041:2005 \& ISO 2631-1: 1997 guidelines. [6,7] The Tri-axial seat pad accelerometer was placed on the seat of the equipment (Figure 3) under investigation and the operator was asked to sit on the pad. The seat pad was so placed that it was aligned to the basi-centric or right-handed orthogonal coordinate system related to the contact surface (Figure 4). The signal transmission cable was routed with sufficient care to avoid interference with the equipment control system. Each operator was briefed about the purpose of the measurement. It was ensured that this measurement did not hinder their regular work. The magnitude of vibration was measured in terms of root mean square (RMS) values of frequency weighted acceleration $\left(A_{\text {eq }}\right.$ in $\left.\mathrm{m} / \mathrm{s}^{2}\right)$. The recorded data was later downloaded to a computer for analysis and interpretation.

Measurements were taken for a minimum of four minutes during operation. Since the operation is not cyclic, information about the average daily duration of exposure was collected from mine officials. The measured RMS values along all axis was multiplied by applicable scale factors $\left(\mathrm{k}_{\mathrm{x}}, \mathrm{k}_{\mathrm{y}}=1.4, \mathrm{k}_{\mathrm{z}}=1\right)$. The axis having the highest RMS acceleration value (after multiplication by the corresponding scale factor) was considered as the dominant axis of vibration. (Table 2)

The prediction of health risk from exposure to equipment vibration primarily depends upon two factors: vibration magnitude along the dominant axis \& duration of exposure in a day. The graphical representation of Health Guidance Caution Zone (HGCZ) in Annex B of ISO 2631-1:1997 was referred for evaluation of exposure risk (Fig 5).[7] HGCZ is the area between a set of two parallel lines corresponding to lower and upper limits. There are two such sets in the graph. The first one uses the duration of exposure and acceleration magnitude in RMS values $\left(A_{e q}\right)$ in $x$ and $y$ coordinates respectively to determine the severity of exposure. Evaluation of a point $P(x, y)$ plotted according to duration ( $x$ axis) and magnitude ( $y$ axis) of an exposure was carried out using the criteria summarized below:

Figure 1. Loader hauling from stock pile to Dumper .

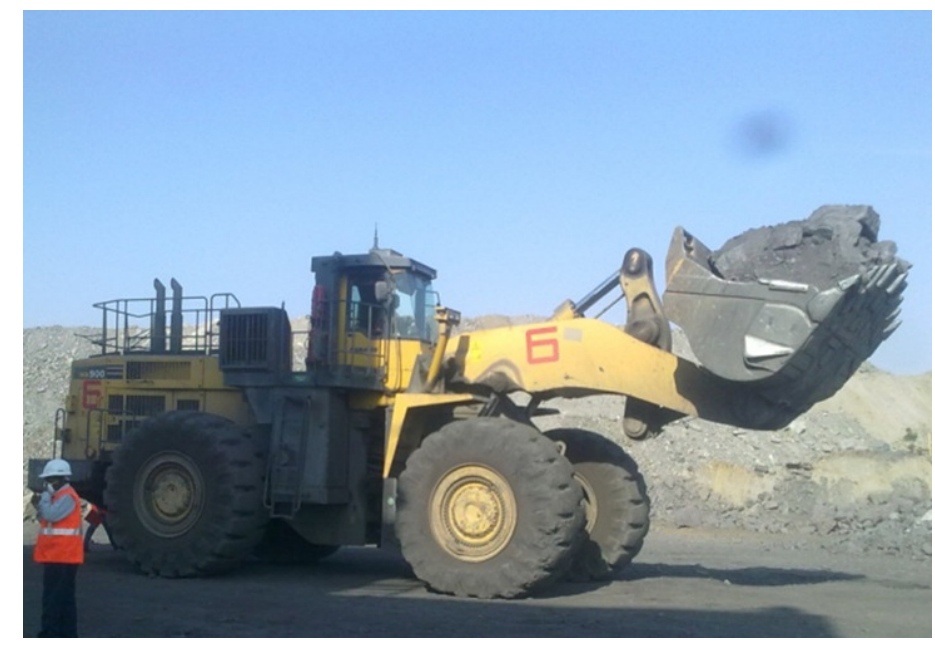


- Exposure below the zone the health effects are not clearly documented [marked as "minimal/no"]

- Inside the zone there is indication of health risk [marked as "moderate"] i.e. there is a probability of vibration induced injury to occur.

- $\quad$ And above the zone, the health risk is quite likely [marked as "high"]

The second set of parallel lines uses Vibration Dose Values (VDV) which is an additional evaluation and not considered in this article. The operation of the loaders and dozers were recorded with a video camera for subsequent critical observation.

\section{Results}

It was noted from mine officials that Dozer operators worked for 3 to 6.5 hours while the Loader operators worked for 5 to 6.5 hours in a day. Among Dozers and loaders, X-axis emerged as dominant axis of vibration for $81 \%$ and $79 \%$ cases respectively. Based on intensity and corresponding duration of exposure in a day, health risk was predicted individually for all machines as per guidelines in ISO 2631-1:1997 which is summarized in Table 1.

Table I Vibration magnitude $\left(A_{e q}\right)$ and health risk assessment .

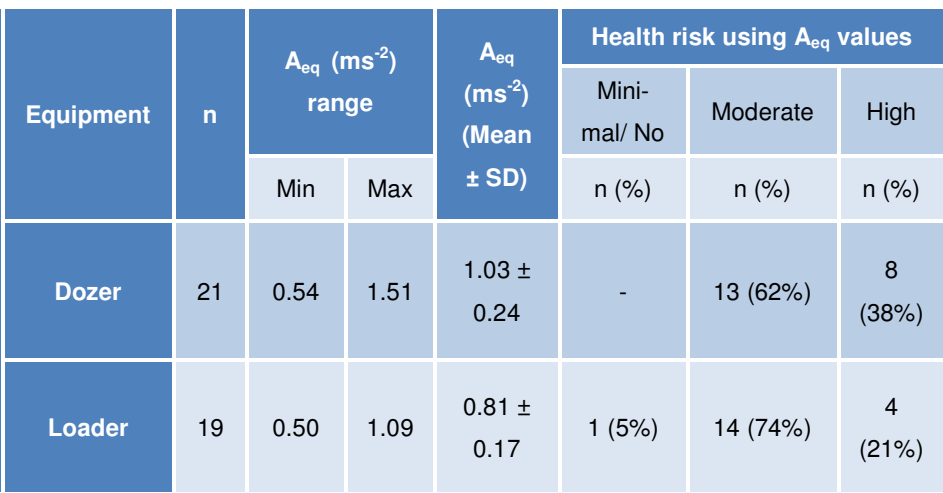

The video record of activity of the two machines showed that:

- Both the machines run usually on rugged uneven terrain.

- $\quad$ For Loaders, the bucket is lowered down and the whole front unit is pushed forward during loading

- After digging is over the Loader bucket unit is raised up slightly by the lifting cylinder. The loaded machine is then reversed back and maneuvered in position to the dumping point or it unloads the material over the Dumper by overturning the bucket by the tilt cylinders.

- The Loader is then maneuvered to the right position and moved forward towards the bench/dump for loading. All the above processes cause the equipment to vibrate.
- Tyres rolling over smaller boulders in the working zone cause vibration intensities to go beyond the usual levels in cases of Loaders.

- $\quad$ Boulders often roll down from above the muck pile during digging and loading which hit the bucket unwarranted causing tremendous shocks.

- Dozers have little scope for vertical movement of blade and no loading operation. The major work load is due to exerting force to move the materials.

- $\quad$ Like Loaders, Dozers also frequently change its direction of motion and its orientation

- Encountering hard rock tips while leveling the wasteland causes sudden shocks

- Dozer operators need not work continuously. So there is a tendency to finish the immediate job requirement and then leave the machine. Rash driving increases the vibration intensity which is also a matter of concern for safety.

\section{Discussion}

The recorded vibration data can be interpreted in two different ways: First with an engineering point of view where the vibration spectrum should be analysed in detail to identify the possible maintenance strategy or modification in the equipment. The second is related to human response to vibration which involves multiplication of the RMS values with appropriate scaling factors to determine the acceleration along dominant axis. (Table 2)This value when considered along with daily duration of exposure, indicates the severity of the exposure with the help of health guidance described in ISO 2631-1:1997. Hence, it is crucial to identify the dominant axis for health risk analysis.

Table II Distribution of dominant axis of vibration

\begin{tabular}{|c|c|c|c|c|c|}
\hline Equipment & $\mathbf{n}$ & & $\mathbf{x}$ & $\mathbf{Y}$ & $\mathbf{Z}$ \\
\hline \multirow{2}{*}{ Dozer } & \multirow{2}{*}{21} & $\begin{array}{c}\text { Without Scaling } \\
\text { Factor }\end{array}$ & $\begin{array}{c}12 \\
(57 \%)\end{array}$ & $\begin{array}{c}1 \\
(5 \%)\end{array}$ & $\begin{array}{c}8 \\
(38 \%)\end{array}$ \\
\hline & & With scaling factor & $\begin{array}{c}17 \\
(81 \%)\end{array}$ & $\begin{array}{c}3 \\
(14 \%)\end{array}$ & $\begin{array}{c}1 \\
(5 \%)\end{array}$ \\
\hline \multirow{2}{*}{ Loader } & \multirow{2}{*}{19} & $\begin{array}{c}\text { Without Scaling } \\
\text { Factor }\end{array}$ & $\begin{array}{c}11 \\
(58 \%)\end{array}$ & $\begin{array}{c}1 \\
(5 \%)\end{array}$ & $\begin{array}{c}7 \\
(37 \%)\end{array}$ \\
\hline & & With scaling factor & $\begin{array}{c}15 \\
(79 \%)\end{array}$ & $\begin{array}{c}2 \\
(11 \%)\end{array}$ & $\begin{array}{c}2 \\
(10 \%)\end{array}$ \\
\hline
\end{tabular}

It is generally perceived that $Z$ (vertical) axis dominates the vibration time history for equipment engaged in loading, hauling or dumping operations. Therefore vibration attenuation measures are aimed mainly to dampen intensity along vertical 
Figure 2. Dozer pushing mill tailings in a tailings dam.

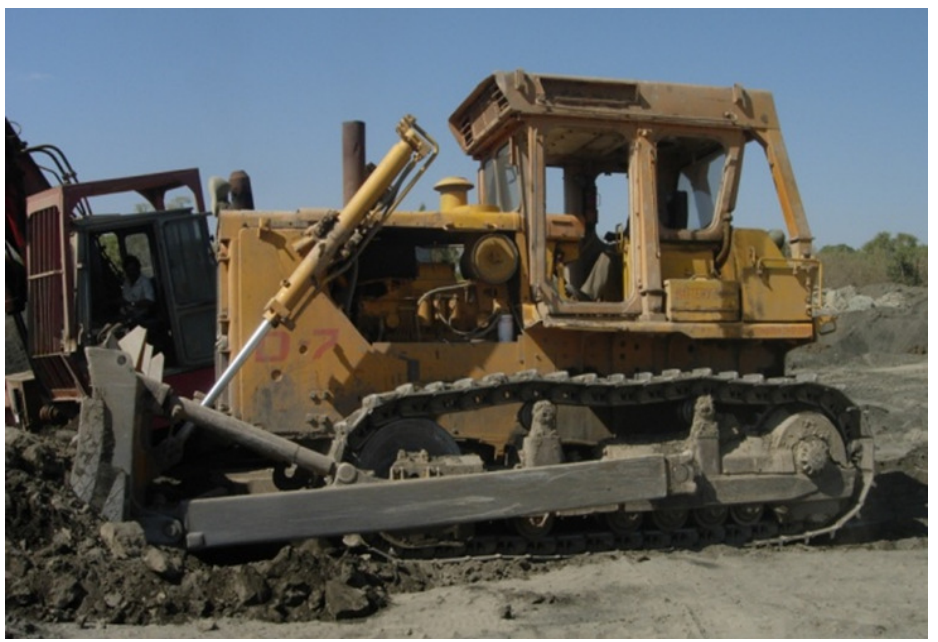

axis. This is true for machineries like Dumpers or Tippers. In a study comprising 18 dumpers, it was evident that all dumpers had $Z$-axis as dominant axis of vibration.[8] Dumpers, in mines, are used to transport the ore or waste. The dumpers, after being loaded by excavators or Loaders, travel on the mine haulage road to the unloading point. It does not frequently change direction and orientation except negotiating curves and change in inclination. Hence vibrations in $X$ and $Y$ directions are less likely compared to $\mathbf{Z}$ direction. Contrary to this, operation of Loader or Dozer is associated with sudden jerks and shocks when the equipment trips over boulders etc. Also the front-back ( $X$ axis) vibration occurs more when these machines push against the stockpile (in case of loaders, while loading) or the dump (in case of dozers while dozing). The operation of both the machine is marked by a characteristic continuous and vigorous alternation between forward and reverse motions which may cause shearing stress on the vertebral column. This may be potentially harmful particularly for neck.

Figure 3. Seat pad Accelerometer .

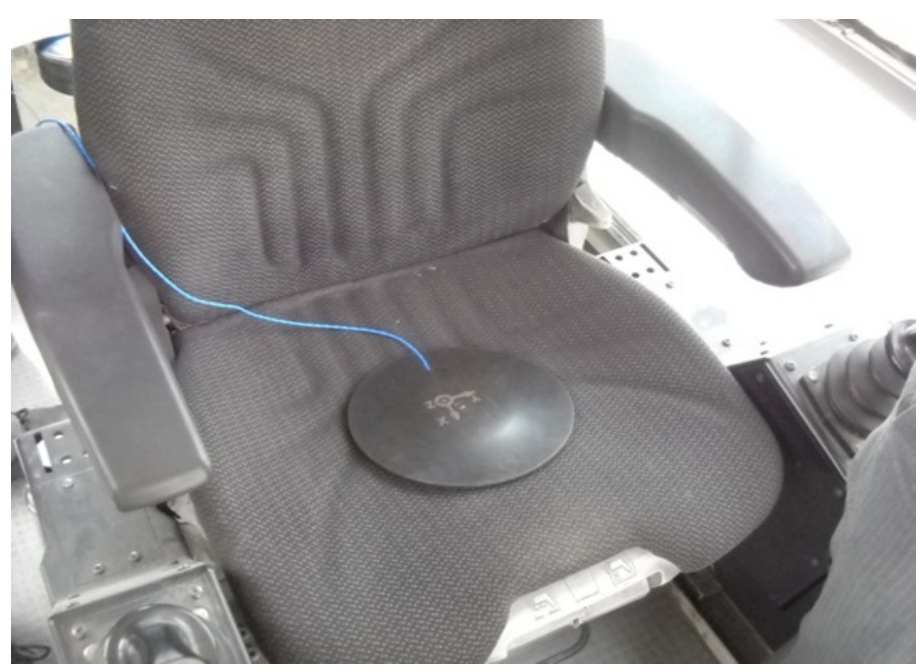

\section{Conclusion}

Mechanical vibration of equipment has multifactorial origin which includes road condition, speed, seat condition, maintenance of equipment among others. Mining being characteristically a continually changing process, all machine need periodical vibration monitoring. The current trend of replacement of ordinary seats with pneumatic suspension seats in dumpers or shovels should also be adopted as engineering control in

Figure 4. Basi-centric axis $(X, Y, Z)$ for Vibration measurement .

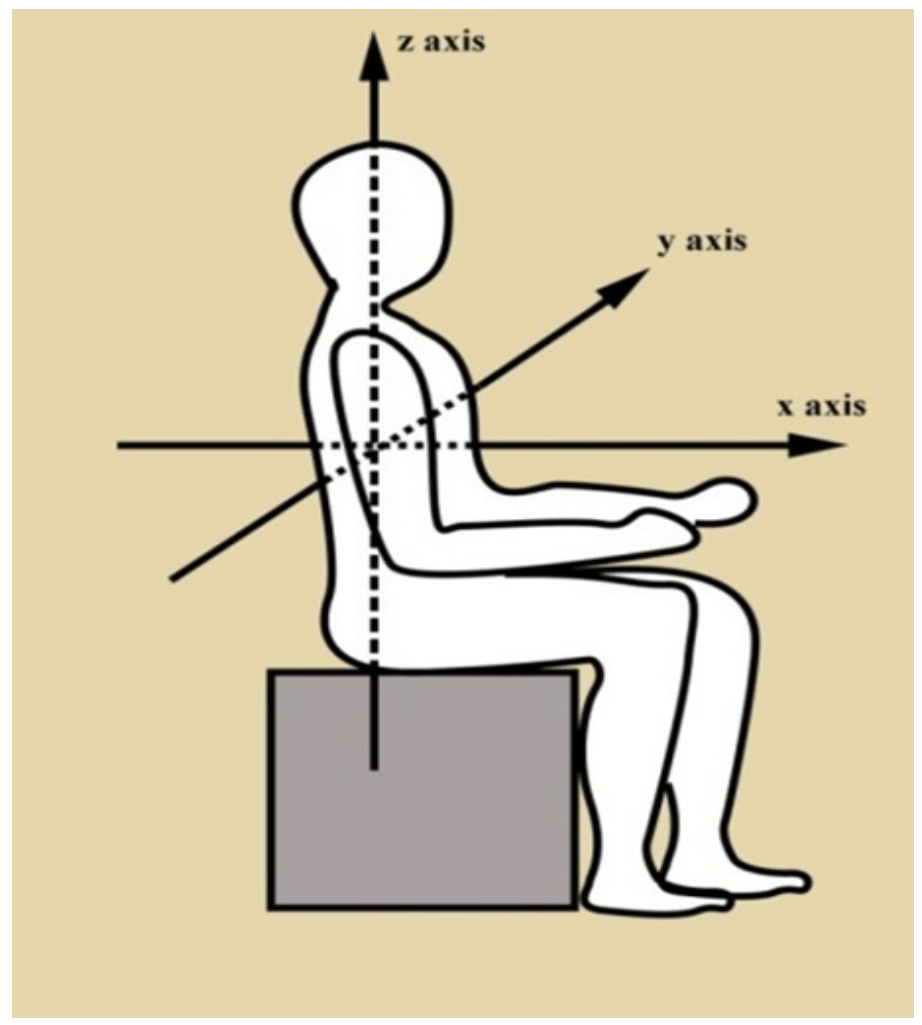

Dozers \& Loaders with a shift of focus towards X-axis instead of techniques which are traditionally aimed at dampening vibration in vertical axis. Translational vibration in $\mathrm{X}$ axis has two components: front \& rear. Vibration in rear direction can be attenuated by lumber supported back rest. Hence, there is much need of research to develop seats which can absorb vibration in $X$-axis, especially in front direction. Considering the vibration hazard potential of these machines mainly emanating from $X$ axis, it is suggested to explore the utility of Seatbelts for Loader and Dozer operators as a vibration safeguard. Speedy or harsh driving of these machines must be avoided. 
Figure 5. [HGCZ] Health Guidance Caution Zone (Annex B: ISO 2631-1:1997).

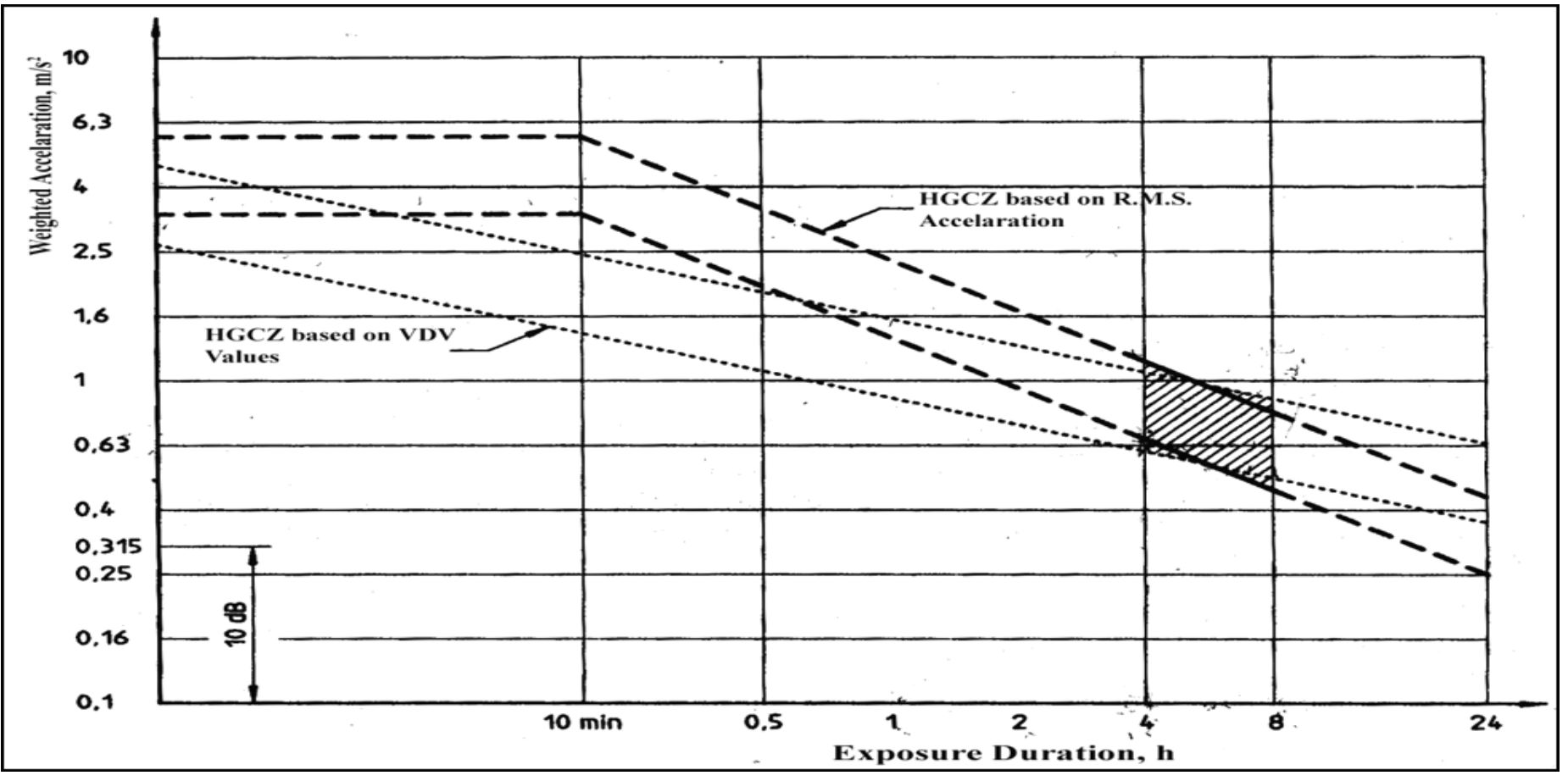

\section{References}

1. Das, SK. Surface Mining Technology (1st ed). Dhanbad (India): Lovely Prakashan, 1994.

2. Kaku, LC. DGMS classified circulars. Dhanbad (India): Lovely Prakashan, 2004.

3. Directorate General of Mines Safety (India). Recommendations of 10th National Conference on Safety in Mines vide DGMS (Tech) (SOMA) Circular No.1 Dated 04.01.2008. para 4.2.

4. Bovenzi, M and Hulshof, CTJ. An updated review of epidemiologic studies on the relationship between exposure to whole-body vibration and low back pain (1986-1997). International Archives of Occupational and Environmental Health, 1999,72(6):351-65.

5. NIOSH, National Institute of Occupational Safety and Health (US), Musculoskeletal disorders and workplace factors: a critical review of epidemiologic evidence for work related musculoskeletal disorders of the neck, upper extremity, and low back, 1997; available at http:/www.cdc.gov/niosh/ docs/97-141/pdfs/97-141.pdf. Last accessed 15 June 2012.

6. International Organization for Standardization. Human response to vibration -- Measuring instrumentation. ISO 8041:2005.

7. International Organization for Standardization. Mechanical vibration and shock -- Evaluation of human exposure to whole-body vibration -- Part 1: General requirements. ISO 2631-1:1997
8. Mandal, BB and Srivastava, AK. Musculoskeletal disorders in dumper operators exposed to whole body vibration at Indian mines. International Journal of Mining, Reclamation and Environment, 2010,24(3):233-43.

\section{Acknowledgement}

The Authors are grateful to the Director, National Institute of Miners' Health, Nagpur (India) for providing all necessary facilities and guidance to conduct the research as well as according permission for publication of the research article. This research article is outcome of work done under Science \& Technology Project "Development of a protocol for evaluation of vibration hazard potential for mining equipment" sponsored by the Ministry of Mines, Govt. of India. 